\title{
Parallel Coordination Control of Multi-Port DC-DC Converter for Stand-Alone Photovoltaic-Energy Storage Systems
}

\author{
Yuxin Liang, Hui Zhang, Mingqiao Du, and Kai Sun
}

\begin{abstract}
Aiming at the low inertia DC micro-grid poor bus voltage quality and the energy storage SOC balanced problem, considering the urgent demand of high up/down ratio, electrical isolation and high-efficiency converter for distributed micro-source. An improved virtual capacitor (IVC) parallel coordination control strategy based on multi-port isolated DC-DC converter is proposed. First, MPIC is used to replace the traditional Buck/Boost circuit to achieve the electrical isolation from the micro sources of the energy storage system. Secondly, by analogy of IVC control, design the control frame of single voltage outside circle and multiple currents inside the ring, IVC control suitable for Four-port isolated DC-DC converter(FPIC) is obtained. Then, the parallel and coordinated control strategy under the control of IVC for multiple energy storage interface converters is established.
\end{abstract}

Index Terms - DC micro-grid, improved virtual capacitor control, inertia, multi-port converter.

\section{INTRODUCTION}

$\mathrm{M}$ ULTI-PORT isolation typed DC-DC converter (MPIC) has many advantages, such as electrical isolation, promotion/ step-down ratio, two-way power flow and simple soft switch control [1], [2]. It is cascaded by CLLC resonant converter and staggered Buck/Boost converter and is widely used in distributed generation systems [3], [4], electric vehicles and other emerging energy conversion systems [5],[6]. With the increase of DC micro-sources and DC loads, the DC micro-grid starts to rise. However, the DC micro-grid itself has low inertia, and its bus voltage is vulnerable to power fluctuations caused by intermittent renewable energy and local load changes [7]-[9]. Especially in off-grid mode, the DC micro-grid can only rely on the energy

Manuscript received July 14, 2020; accepted September 6, 2020. Date of publication September 30, 2020; date of current version September 22, 2020. This work was supported in part by the Delta Power Electronics Research and Education Development Program under Grant DREM2019005, in part by the National Science Foundation of China under Grant 51807104, in part by the National Science Foundation of China under Grant 51877175, and in part by the Key Research and Development Program of Shaanxi Province under Grant 2017zdxm-gy-003. (Corresponding author: Kai Sun.)

Y. Liang, H. Zhang, and M. Du are with the College of Electrical Engineering, Xi'an University of Technology, Xi'an, 710000, China (e-mail:1185816799@ qq.com; zhangh@xaut.edu.cn; 798169975@qq.com).

K. Sun is with the State Key Laboratory of Power Systems, Department of Electrical Engineering, Tsinghua University, Beijing, 100084, China (e-mail: sun-kai@mail.tsinghua.edu.cn).

Digital Object Identifier 10.24295/CPSSTPEA.2020.00020 storage system to adjust the voltage and power balance of the DC bus, which puts forward higher requirements on the capacity, output characteristics and cost of the energy storage equipment [10], [11]. Therefore, this is not conducive to the promotion and maintenance of the micro-grid. At the same time, it is necessary to propose a virtual inertia control strategy for isolated DC-DC converters in view of the urgent demand of distributed microsources for high lift/drop ratio, electrical isolation, and efficient converters. At present, the research on virtual inertia control of DC micro-grid mainly focuses on AC/DC field.

For example, the control of virtual synchronous generator of AC micro-grid is introduced into bus voltage control of DC micro-grid by analogy [12] and proposed a corresponding virtual capacitor control (VC) strategy to Enhance the inertia and stability of the DC micro-grid. But its virtual capacitance value is fixed, so it is difficult to adapt to the speed of voltage change under different load disturbance.

Therefore, Research [13] establishes the relationship between the virtual capacitor and the bus voltage changed rate, and proposes a flexible virtual inertia Flexible Virtual Inertia (FVI) controlled strategy to realize the virtual capacitor follows the voltage adaptive change. Still, the constraints on the critical parameters in the article condition is independent of each other, and no stable operating boundary has been established. Research [14] based on reference [13], by building an index set that satisfies the Stable operation of VSC with multiple constraints, within the multiple constraints range, the flexible adjustment of the virtual capacitance can be used as much as possible to provide inertial support for the DC micro-grid .

It should be pointed out that although the FVI control used in Research [13] and [14] slows the speed of deviation from the rated value when the bus voltage is disturbed, it brings new problems that the voltage recovery time is too long, which will inevitably bring security and stability to the micro-grid Negative Effects.

The energy storage converters in the above documents are all Buck/Boost non-isolated circuits, which have the advantages of low cost, lightweight, and simple structure [15], [16] mainly used in low voltage, high current applications. However, the non-isolated circuit has a narrow buck-boost range, which is not suitable for high-voltage gain occasions. And without electrical isolation, the safety of the distributed power system is difficult to be guaranteed.

Therefore, the use of MPIC to replace the traditional Buck/ Boost circuit can protect the operator and the post-level equipment from electrical damage, and reduce the voltage level of the energy storage device [17]. Moreover, due to the 


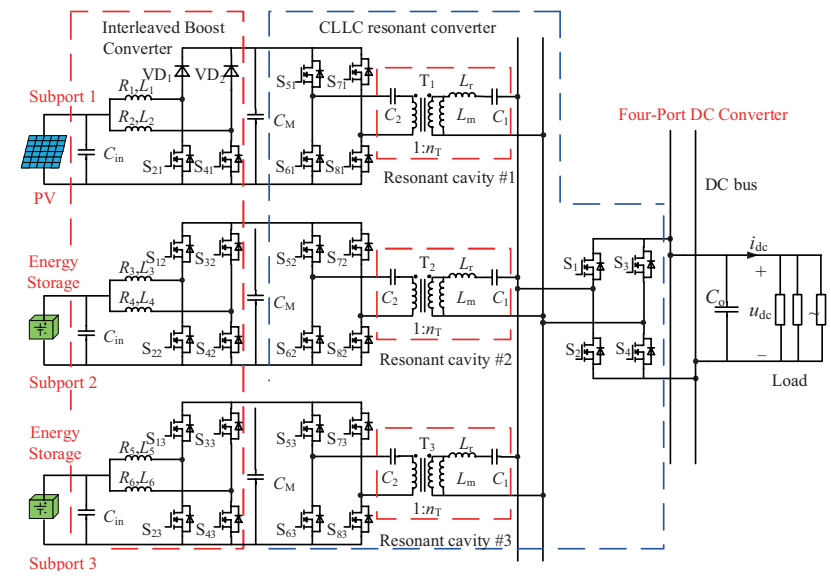

Fig. 1. DC micro-grid structure diagram of photo-voltaic energy storage with FPIC.

extensibility of multiple ports, it is necessary to consider Soc balance and power distribution when multiple energy storage systems are connected in parallel [12], [18]-[20]. In summary, it is of considerable significance to study the VC control applied and the parallel coordination control strategy to isolated DC-DC converters.

Given the above problems, this paper proposes a parallel coordinated control strategy based on virtual capacitor control in the Four-port isolated DC-DC converter (FPIC), which realize the distribution of the output power of the energy storage unit according to the remaining capacity and ensure that the charged state of each energy storage system is balanced.

\section{DC Micro-Grid System Structure}

The optical storage DC micro-grid system shown in Fig. 1 is constructed. Its components are as follows: 1) The photovoltaic unit and two energy storage devices are connected to a $400 \mathrm{~V}$ DC bus through a two-stage isolated bidirectional DCDC converter, and form a three-port DC converter with a DC load; 2) The CLLC resonant circuit is used as the front stage of the two-stage converter, and the interleaved Buck/Boost circuit is used as the rear stage. At cost considerations, the poststage of the photo-voltaic interface converter is replaced with an interleaved boost circuit. In Fig. $1, u_{\mathrm{dc}}$ is the DC bus voltage, $i_{\mathrm{dc}}$ is the DC output current; $n_{\mathrm{T}}$ is the transformer turns ratio; $L_{\mathrm{m}}$ and $L_{\mathrm{r}}$ are the resonance inductance and resonance inductance of the resonator; $C_{1}$ and $C_{2}$ are the resonance capacitance; $C_{\text {in }}, C_{\mathrm{M}}$ and $C_{\mathrm{o}}$ are the input of FPIC respectively Capacitor, intermediate stage capacitor and output capacitor. The specific control method is as follows.

1) For the front-end CLLC resonant circuit, the high-side full bridge, and the two low-side full bridges apply a duty cycle of 50 percent to the switch tubes $\mathrm{S}_{1}, \mathrm{~S}_{4}, \mathrm{~S}_{5 i}, \mathrm{~S}_{8 i}(i=1,2)$. Its switching frequency is the control signal of resonant frequency (in-phase). The other switching tube applies a complementary control signal. It should be pointed out that under ideal conditions, the working state of each resonant cavity is no different from the three-port DC converter.
2) For the post-stage interleaved Buck/Boost circuit, it is assumed that the photo-voltaic converter has been working in the MPPT state and the energy storage converter (ESC) operates in IVC mode. To the lower arm switch tubes $\mathrm{S}_{22}$ and $\mathrm{S}_{42}$, a driving signal with a phase difference between $180^{\circ}$ and the same duty ratio is applied, and the driving signals of the upper and lower arm switch tubes are controlled to be complementary.

\section{IMPRoved Virtual CAPACITANCE CONTROL AND Parallel Coordination Control of DC Micro-Grid}

\section{A. The Virtual Capacitor Design Principles}

In the DC micro-grid, the disturbances such as changes in the output of renewable energy and load switching will cause frequent fluctuations in the DC bus voltage and deteriorate the power quality. Concerning the frequency modulation control of the virtual synchronous generator, the charge and discharge characteristics and damping characteristics of the real capacitor are simulated in the droop control of the ESC. The disturbance suppression ability of the DC bus voltage is enhanced. The virtual capacitance equation of the ESC is as follows[15], [16]:

$$
I_{\mathrm{set}}-i_{\mathrm{dc}}-D_{\mathrm{b}} \Delta_{\mathrm{u}}=\frac{P_{\mathrm{set}}}{U_{\mathrm{n}}}-\frac{P_{\mathrm{o}}}{U_{\mathrm{n}}}-D_{\mathrm{b}}\left({ }_{u_{\mathrm{dc}}^{*}}^{*}-U_{\mathrm{n}}\right)=C_{\mathrm{vir}} \frac{d u_{\mathrm{dc}}^{*}}{\mathrm{~d} t}
$$

Where $C_{\text {vir }}$ is the virtual capacitance, $D_{\mathrm{b}}$ is the voltage damping coefficient, $I_{\text {set }}$ is the DC output current reference, $P_{\text {set }}$ and $P_{\mathrm{o}}$ are the DC output power reference and actual value, $u_{\mathrm{dc}}{ }^{*}$ and $U_{\mathrm{n}}$ are the reference and rating of DC bus voltage.

When the DC micro-grid is running in a steady state can be obtained:

$$
u_{\mathrm{dc}}^{*}=\left(U_{\mathrm{n}}+\frac{I_{\mathrm{set}}}{D_{\mathrm{b}}}\right)-\frac{1}{D_{\mathrm{b}}} i_{\mathrm{dc}}=U_{\mathrm{ref}}-n i_{\mathrm{dc}}
$$

Where $U_{\text {ref }}$ is the no-load output voltage on the DC side, and $n$ is the droop coefficient.

For isolated DC micro-grids containing FPIC, when the load is disturbed, $C_{\mathrm{vir}}$ is expected to be more significant to reduce the rate of change of the bus voltage; after the disturbance, the bus voltage will be restored quickly. VC control is a kind of constant virtual capacitance control with certain limitations, which cannot meet the above requirements at the same time. Therefore, the control principle of IVC control under FPIC is shown in Fig. 2.

Where $C_{\mathrm{v} 0}$ is the initial virtual capacitance, $k_{\mathrm{u}}$ is the voltage tracking coefficient. It can be seen from the above figure that the IVC control is determined by the difference between the DC bus voltage change rate $\mathrm{d} u_{\mathrm{dc}}{ }^{*} / \mathrm{d} t$, the difference between the DC bus given voltage $u_{\mathrm{dc}}{ }^{*}$ and its rated voltage $U_{\mathrm{n}}$. To enable the ESC to adjust $C_{\mathrm{vir}}$ according to the voltage change dynamically, 


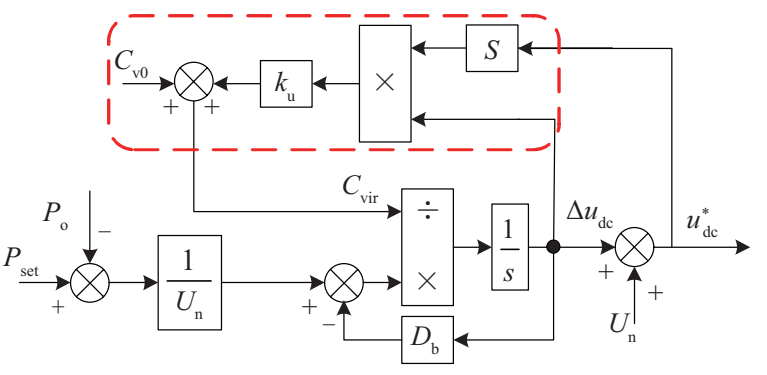

Fig. 2. Improved virtual capacitor control principle.

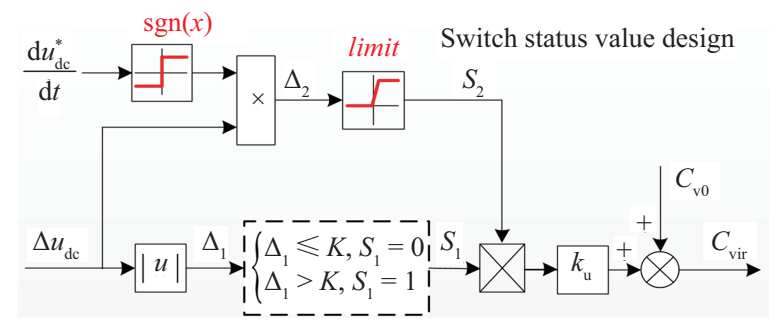

Fig. 3. Principle of switch action under IVC control.

$C_{\text {vir }}$ is written here as a function of the voltage change rate $\mathrm{d} u_{\mathrm{dc}}{ }^{*} /$ $\mathrm{d} t$ and the voltage change amount $\left|\Delta u_{\mathrm{dc}},\right| \Delta u_{\mathrm{dc}} \mid>K$.

$$
C_{\mathrm{vir}}=C_{\mathrm{vo}}+k_{\mathrm{u}}\left(u_{\mathrm{dc}}^{*}-U_{\mathrm{n}}\right) \frac{\mathrm{d} u_{\mathrm{dc}}^{*}}{\mathrm{~d} t},\left|\Delta u_{\mathrm{dc}}\right|>K
$$

Where $K$ is the limited value of the voltage change, set according to the allowable bus voltage fluctuation range of the micro-grid.

To improve the engineering practicality of the algorithm and simplify its parameter selection process, IVC control was further optimized to obtain its switching action principle, as shown in Fig. 3.

In Fig. $3, \Delta_{1}=\left|\Delta u_{\mathrm{dc}}\right|, \Delta_{2}=\operatorname{sgn}\left(\mathrm{d} u_{\mathrm{dc}}{ }^{*} / \mathrm{d} t\right) \Delta u_{\mathrm{dc}}, \mathrm{S}_{1}$ and $\mathrm{S}_{2}$ are all on/off state values. Here, the disturbance caused by load impact is simply analyzed. The relationship between the first compared $\Delta_{1}$ and $K$. If $\Delta_{1} \leqslant K, S_{1}=0, C_{\mathrm{vir}}=C_{\mathrm{v} 0}$; If $\Delta_{1}>K, S_{1}=1$, $C_{\text {vir }}$ by $\Delta u_{\mathrm{dc}}$ and $\mathrm{d} u_{\mathrm{dc}}{ }^{*} / \mathrm{d} t$ product decision, and $\mathrm{d} u_{\mathrm{dc}}{ }^{*} / \mathrm{d} t$ symbols times $\Delta u_{\mathrm{dc}}$ are equal to $\Delta_{2}$; if $\Delta_{1}>K, \Delta_{2}>0$, then $S_{2}=\Delta_{2}, C_{\text {vir }}=$ $C_{\mathrm{v} 0}+k_{\mathrm{u}} S_{2} ;$ if $\Delta_{1}>K, \Delta_{2} \leqslant 0$, then $S_{2}=0, C_{\mathrm{vir}}=C_{\mathrm{v} 0}$.

In conclusion, the final expression of virtual capacitance corresponding to IVC control as follows.

$$
\begin{cases}C_{\mathrm{vir}}=C_{\mathrm{v} 0} & \Delta_{1} \leqslant K \\ C_{\mathrm{vir}}=C_{\mathrm{v} 0}+k_{\mathrm{u}} S_{2} & \Delta_{1}>K \text { and } \Delta_{2}>0 \\ C_{\mathrm{vir}}=C_{\mathrm{v} 0} & \Delta_{1}>K \text { and } \Delta_{2} \leqslant 0\end{cases}
$$

\section{B. The DC Micro-Grid Parallel Coordination Control Strategy}

The energy storage devices widely used in DC micro-grids include lead-acid cells and lithium batteries. As one of the indicators to measure the capacity of such batteries, the state of charge (SOC) plays an integral part in the power distribution of energy storage units.

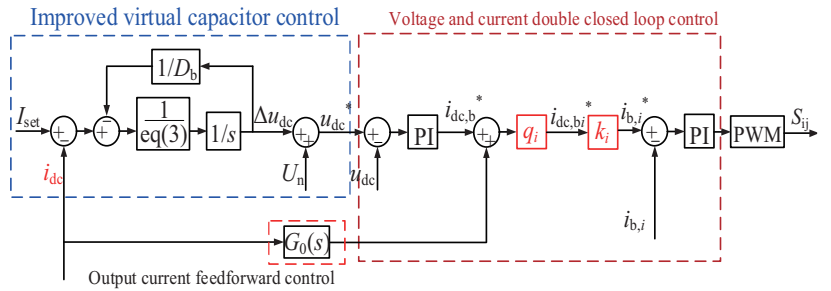

Fig. 4. FPIC multiple energy storage parallel and coordinated control block diagram.

To effectively manage and efficiently use energy storage devices in FPIC, Fig. 4 shows the principle block diagram of multiple energy storage and coordinated control, which mainly includes IVC control, voltage and current dual-loop control and output current feed-forward control. $G_{0}(s)$ is the output current feed-forward function utilized to eliminate the bus voltage overshoot caused by sudden load changes. The voltage and current double-loop control are composed of the DC bus voltage outer loop and the input current inner loop.

Then, it creates a modulated wave and generates a duty cycle through PWM control. Among them, $i_{\mathrm{dccb}}$ " is the reference value of the total output current transmitted by the energy storage unit to the DC side, $i_{\mathrm{dc}, b i}{ }^{*}$ is the reference value of the output current transmitted by each energy storage unit to the DC side, and $i_{\mathrm{b}, i}{ }^{*}$ is the inductance of each energy storage unit Reference value of current $(i=1,2)$.

Fig. 4 makes corresponding adjustments to the output current feed-forward function, and adds the energy storage unit power distribution coefficient $q_{i}$ and current conversion coefficient $k_{i}$ to the voltage and current dual-loop control, aiming to accurately and reasonably allocate the output power of each energy storage unit $(i=1,2)$. It is not hard to find that the outer loop voltage reference value of Fig. 2 is produced by IVC control, and the voltage and current loop is composed of a voltage outer loop and multiple current inner loops. The output power of the energy storage unit is allocated by configuring the currents $i_{\mathrm{dccb}}{ }^{*}$. Finally, the PWM module generates control signals for each energy storage interface converter.

The power distribution of the energy storage unit is given by the proportion of the remaining capacity of each energy storage unit to the total remaining capacity. The expression of the power distribution coefficient $q_{i}$ can be obtained as follows.

$$
q_{i}=\frac{P_{\text {bat } i}^{\text {max }} \mathrm{SOC}_{i}}{\sum_{i} P_{\text {bat } i}^{\text {max }} \mathrm{SOC}_{i}}
$$

Where $P_{\mathrm{bat}, i}^{\max }$ is the maximum charge and discharge power of the energy storage unit, and $\mathrm{SOC}_{i}$ is the remaining state of charge of the energy storage unit $(i=1,2)$.

Ignoring the energy loss of FPIC, the input and output power balance can be obtained.

$$
u_{\mathrm{b}} i_{\mathrm{b}}=u_{\mathrm{dc}} i_{\mathrm{dc}, \mathrm{b}}
$$


Write the state variable in (6) as the sum of the steadystate quantity and the small disturbance quantity, and perform linearization processing to obtain (7).

$$
I_{\mathrm{b}} \Delta u_{\mathrm{b}}+U_{\mathrm{b}} \Delta i_{\mathrm{b}}=I_{\mathrm{dc}, \mathrm{b}} \Delta u_{\mathrm{dc}}+U_{\mathrm{dc}} \Delta i_{\mathrm{dc}, \mathrm{b}}
$$

Ignoring $\Delta u_{\mathrm{b}}(s)$ and $\Delta u_{\mathrm{dc}}(s)$ in (6), the transfer function between $\Delta i_{\mathrm{dc}, \mathrm{b}}(s)$ and $\Delta i_{\mathrm{b}}(s)$ can be obtained as shown in (8).

$$
G_{\mathrm{ii}}(s)=\frac{U_{\mathrm{dc}}}{U_{\mathrm{b}}}
$$

It can be seen from (8) that the value of the transfer function $G_{\mathrm{ii}}(s)$ is the ratio of the DC bus voltage effective value $U_{\mathrm{dc}}$ and the energy storage unit voltage effective value $U_{\mathrm{b}}$, taking into account the difference in the voltage of each energy storage unit port, to accurately control the storage The expression of the current conversion coefficient $k_{i}$ of the output power of the energy unit is as follows.

$$
k_{i}=\frac{U_{\mathrm{dc}}}{U_{\mathrm{b}, i}}
$$

Where $U_{\mathrm{b}, i}$ is the effective value of the output voltage of each energy storage unit.

In this section, the output current feed-forward transfer function is adapted accordingly. As can be observed in Fig. 1, the output power of the photo-voltaic unit and the output power of the energy storage unit are collected to the high-voltage side of the full-bridge through multiple ports. The same can be obtained from the input and output power balance principle.

$$
\begin{aligned}
& P_{\text {ref }}=P_{\mathrm{pv}}+P_{\mathrm{bat}} \\
& i_{\mathrm{dc}}=i_{\mathrm{dc}, \mathrm{p}}+i_{\mathrm{dc}, \mathrm{b}}
\end{aligned}
$$

According to the principle of input and output power balance, (12) can be obtained. The expression of the transfer function $G_{0}(s)$ is as follows.

$$
\begin{gathered}
\left\{\begin{array}{l}
u_{\text {bat }} i_{\text {bat }}=i_{\mathrm{dc} \_b} U_{\mathrm{N}} \\
i_{\mathrm{dc}}=i_{\mathrm{dc} \_\mathrm{b}}+i_{\mathrm{dc} \_\mathrm{p}}
\end{array}\right. \\
G_{0}(s)=\frac{i_{\mathrm{dc} \_\mathrm{b}}}{i_{\mathrm{dc}}}=\frac{U_{\mathrm{N}} i_{\mathrm{dc} \_\mathrm{b}}}{U_{\mathrm{N}} i_{\mathrm{dc}}}=\frac{P_{\mathrm{bat}}}{P_{\text {ref }}}=\frac{P_{\text {ref }}-P_{\mathrm{pv}}}{P_{\text {ref }}}
\end{gathered}
$$

Where, $P_{\text {ref }}=U_{\mathrm{n}}^{2} I_{\mathrm{dc}} / U_{\mathrm{dc}}$, is the reference value of load power, $P_{\mathrm{pv}}$ is photo-voltaic output power, $P_{\text {bat }}$ is photovoltaic output power, $i_{\mathrm{dc} \_\mathrm{p}}$ and $i_{\mathrm{dc} \_\mathrm{b}}$ represent the output current transferred from PV and energy storage unit to the HVDC side.

It should be noted that the transmission of energy storage power distribution signals depends on the Serial Communication Interface (SCI) technology. This section mainly studies the energy storage power distribution strategy of FPIC under IVC control, and does not address the communication technology.
TABLE I

Simulation Parameters of FPIC

\begin{tabular}{lcc}
\hline \hline Symbol & Parameter name & Numerical value \\
\hline$n_{\mathrm{T}}$ & Transformer ratio & 4 \\
$L_{\mathrm{r}} / \mu \mathrm{H}$ & Resonant inductance & 437.5 \\
$C_{\mathrm{l}} / \mathrm{nF}$ & Resonant capacitor & 10 \\
$C_{2} / \mathrm{nF}$ & Resonant capacitor & 160 \\
$C_{\mathrm{in}}, C_{\mathrm{M}} / \mu \mathrm{F}$ & Input capacitance & 141 \\
$C_{\mathrm{o}} / \mu \mathrm{F}$ & Output capacitance & 300 \\
$L_{\mathrm{m}} / \mu \mathrm{H}$ & Excitation inductance & 562.5 \\
$L_{1-4} / \mu \mathrm{H}$ & Staggered inductance & 80 \\
$P_{\mathrm{o}} / \mathrm{kW}$ & Maximum output power & 4 \\
$C_{\mathrm{v} 0} / \mathrm{mF}$ & Virtual capacitance & 1 \\
$D_{\mathrm{b}}$ & Damping coefficient & 0.25 \\
$f_{\mathrm{CLLC}} / \mathrm{kHz}$ & Switching frequency & 100 \\
$f_{\mathrm{Boost}} / \mathrm{kHz}$ & Switching frequency & 100 \\
$U_{\mathrm{dc}} / \mathrm{V}$ & DC bus voltage & 400 \\
$u_{\mathrm{bat}} / \mathrm{V}$ & Energy storage output voltage & 48 \\
$u_{\mathrm{pv}} / \mathrm{V}$ & PV output voltage & 55 \\
\hline \hline
\end{tabular}

TABLE II

FPiC Operation Status Table Under Load Disturbance $\left(P_{\mathrm{pv}}=3 \mathrm{~kW}\right)$

\begin{tabular}{ll}
\hline \hline Time & Operating status \\
\hline $0 \mathrm{~s}-0.2 \mathrm{~s}$ & $\begin{array}{l}\text { With a load of } 3 \mathrm{~kW} \text {, only the photo-voltaic unit works. } \\
\text { Suddenly increase the } 2.4 \mathrm{~kW} \text { load, the energy storage device }\end{array}$ \\
$0.2 \mathrm{~s}-0.4 \mathrm{~s}$ & $\begin{array}{l}\text { switches to discharge mode to meet the power required by the } \\
\text { load. }\end{array}$ \\
& $\begin{array}{l}\text { The load is restored to } 3 \mathrm{~kW} \text {, and the energy storage device } \\
\text { stops working. } \\
\text { Suddenly reduce the } 2.4 \mathrm{~kW} \text { load, the energy storage device }\end{array}$ \\
$0.6 \mathrm{~s}-0.8 \mathrm{~s}$ & $\begin{array}{l}\text { switches to the charging mode, and absorbs the excess power of } \\
\text { the micro-grid. }\end{array}$ \\
\hline \hline
\end{tabular}

\section{SimUlation Verification}

To verify the validity of the above mentioned FPIC multiple energy storage parallel and coordinated control strategy and the correctness of theoretical analysis, an optical storage DC microgrid system with FPIC was built-in the Simulink simulation environment. The simulation parameters are shown in Table I.

\section{A. The Power Distribution of the Same Capacity}

When the capacity of the energy storage unit is the same, the operating status of the FPIC under load disturbance is shown in Table II. Fig. 5 is the power simulation waveform of each unit of FPIC system.

The photo-voltaic unit kept the productive $3 \mathrm{~kW}$ output unchanged during the full simulation process. When the load of $0.2 \mathrm{~s}$ suddenly increased to $5.4 \mathrm{~kW}$, the output power of the photo-voltaic group was insufficient, and the energy storage unit began to produce electricity. The output power of the energy storage unit No. 1 and No. 2 were $1.2 \mathrm{~kW}$. 

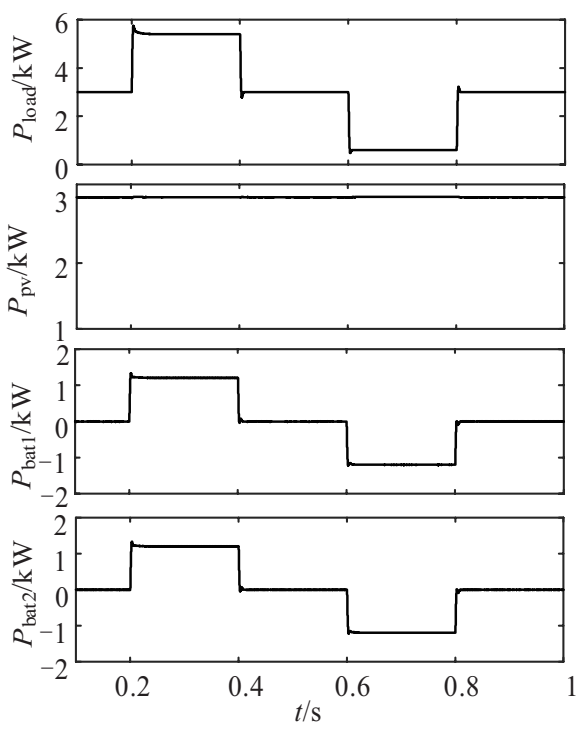

Fig. 5. Power simulation waveform of each unit.

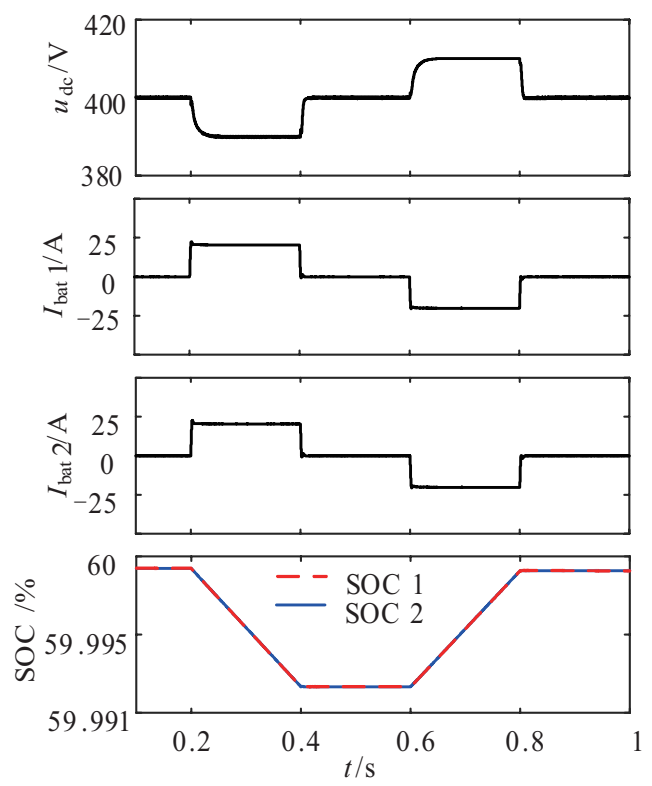

Fig. 6. FPIC simulation waveform under the same energy storage capacity.

When the $0.6 \mathrm{~s}$ load suddenly drops to $600 \mathrm{~W}$, the output power of the photo-voltaic unit overflows, and the energy storage unit immediately changes to the charging mode. At this time, the output power of both energy storage devices is $-1.2 \mathrm{~kW}$. The simulation results demonstrate that under the same energy storage capacity, the proposed control strategy successfully achieves the productive power output of the two energy storage units.

Fig. 6 displays the simulated waveform of DC bus voltage, inductor current of the energy storage converter, and energy storage load SOC under IVC control. It can be viewed in conjunction with Fig. 5 that the trend of the DC bus voltage change fully complies with the expected target of the IVC control strategy. The absolute value of the inductor current of the two energy storage converters is $20 \mathrm{~A}$, which matches
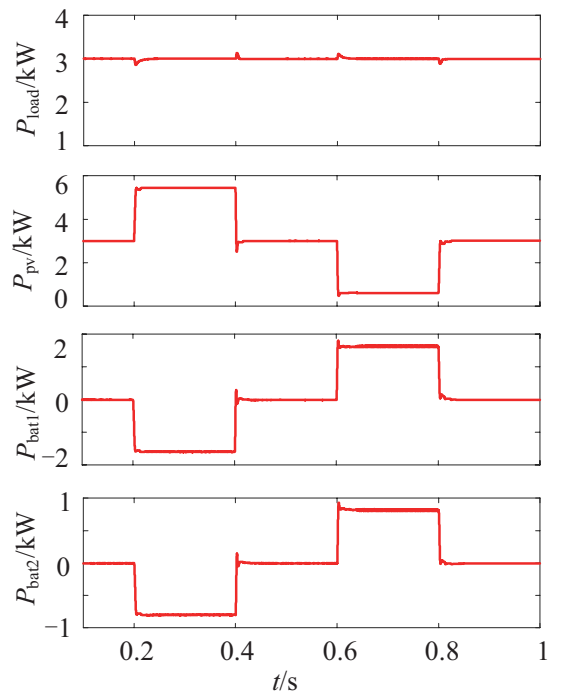

Fig. 7. Power simulation waveform of each unit.
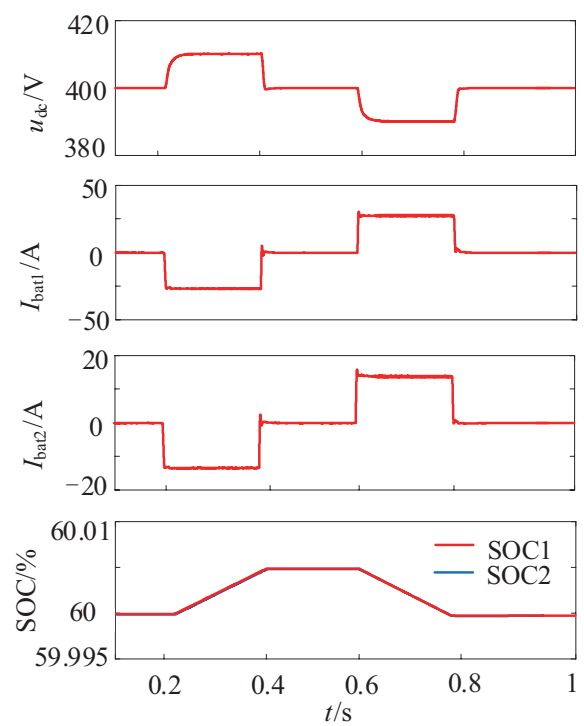

Fig. 8. FPIC simulation waveform under the different energy storage capacity.

the charge and discharge power of the energy storage unit. In the simulation process, the SOC of two energy storage units with the same capacity is always consistent, indicating that the proposed control strategy successfully achieving the SOC balance of the energy storage unit.

\section{B. The Power Distribution of Different Capacities and Photo- Voltaic Fluctuations}

As shown in Fig. 7 and 8 , at $0-0.2 \mathrm{~s}$, the load is $3 \mathrm{~kW}$, the radiation intensity is $1000 \mathrm{~W} / \mathrm{m}^{2}$ and only the photo-voltaic cell is working. At $0.2 \mathrm{~s}$, the radiation intensity increases to 1500 $\mathrm{W} / \mathrm{m}^{2}$ and the photo-voltaic cell charges the energy storage unit while supplying power to the load. At $0.4 \mathrm{~s}$, the radiation intensity returned to $1000 \mathrm{~W} / \mathrm{m}^{2}$ and the energy storage unit stopped working. At $0.6 \mathrm{~s}$, the radiation intensity was suddenly reduced to $500 \mathrm{~W} / \mathrm{m}^{2}$, the output of the photovoltaic cell was reduced by half and the energy storage device was switched to 


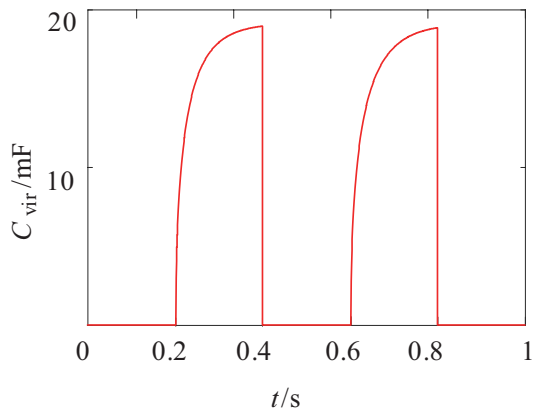

Fig. 9. Simulation waveform of virtual capacitor control.

discharge mode. At $0.8 \mathrm{~s}$, the radiation intensity was restored to $1000 \mathrm{~W} / \mathrm{m}^{2}$ and the energy storage unit stopped working. It can be seen that the energy storage unit adaptively adjusts the output power with the change of photo-voltaic output in the whole process. This is in line with the intended control objectives.

Fig. 9 shows the simulation waveform of virtual capacitor control of the PV unit MPPT control parallel energy storage device when the output power of the PV unit is suddenly changed. It can be seen that the virtual capacitor control can actively respond to the photo-voltaic cell output change and effectively deal with the bus voltage mutation caused by the photo-voltaic output change.

The above result shows that under different energy storage capacity conditions, the proposed control strategy successfully realized the two energy storage units to distribute productive power according to their remaining capacities. The effectiveness and correctness of the proposed control strategy are checked.

\section{CONCLUSION}

This paper takes FPIC control as the research object. To realize the balance of energy storage SOC and the proportional relation of output power, a parallel and coordinated control strategy suitable for FPIC is proposed. Simulink simulation is used to compare different energy storage capacities. The bus voltage transient waveform, power waveform, and SOC waveform, the conclusion is as follows.

For each micro-source sharing a full high-voltage bridge, a control framework with a voltage outer loop and multiple current inner loops is used to construct a power distribution loop on the current inner loop. The energy storage system can accurately distribute the output power according to the proportion of the remaining capacity of each energy storage unit to the total remaining capacity to ensure the safe and reliable operation of the optical storage DC micro-grid system.

Considering the good scalability of the FPIC topology, an optical storage system structure based on a multi-port optical storage unit is proposed to provide a feasible solution for the popularization and application of large-capacity optical storage systems in DC micro-grid.

\section{REFERENCES}

[1] Z. U. Zahid, Z. M. Dalala, R. Chen, B. Chen, and J. S. Lai, "Design of bidirectional DC-DC resonant converter for vehicle-to-grid (V2G) applications," in IEEE Transactions on Transportation Electrification, vol. 1, no. 3, pp. 232-244, Oct. 2015.

[2] J. H. Jung, H. S. Kim, M. H. Ryu, and J. W. Baek, "Design methodology of bidirectional CLLC resonant converter for high-frequency isolation of DC distribution systems," in IEEE Transactions on Power Electronics, vol. 28, no. 4, pp. 1741-1755, Apr. 2013.

[3] D. Tan and D. Novosel, "Energy challenge, power electronics \& systems (PEAS) technology and grid modernization," in CPSS Transactions on Power Electronics and Applications, vol. 2, no. 1, pp. 3-11, Apr. 2017.

[4] N. Farzam, Y. Li, A. B. Nassif, and T. Kang, "Optimal design and operation of a remote hybrid microgrid," in CPSS Transactions on Power Electronics and Applications, vol. 3, no. 1, pp. 3-13, Mar. 2018.

[5] D. Divan and P. Kandula, "Distributed power electronics: An enabler for the future grid," in CPSS Transactions on Power Electronics and Applications, vol. 1, no. 1, pp. 57-65, Dec. 2016.

[6] S. Inoue and H. Akagi, "A bidirectional DC-DC converter for an energy storage system with galvanic isolation," in IEEE Transactions on Power Electronics, vol. 22, no. 6, pp. 2299-2306, Nov. 2007.

[7] N. Soni, S. Doolla, and M. C. Chandorkar, "Improvement of transient response in microgrids using virtual inertia," in IEEE Transactions on Power Delivery, vol. 28, no. 3, pp. 1830-1838, Jul. 2013.

[8] X. Zhang, N. Zhang, F. Long, and G. Peng, "Research of the impacts on static voltage stability of distribution networks with distributed generation from different aspects," in Power System Protection and Control, vol. 45, no. 6, pp. 120-125, Mar. 2017.

[9] T. Dragicevic, J. M. Guerrero, J. C. Vasquez, and D. Skrlec, "Supervisory control of an adaptive-droop regulated DC microgrid with battery management capability," in IEEE Transactions on Power Electronics, vol. 29, no. 2, pp. 695-706, Feb. 2014.

[10] A. Sangwongwanich, G. Angenendt, S. Zurmuhlen, Y. Yang, D. Sera, D. U. Sauer, and F. Blaabjerg, "Enhancing PV inverter reliability with battery system control strategy," in CPSS Transactions on Power Electronics and Applications, vol. 3, no. 2, pp. 93-101, Jun. 2018.

[11] C. Wang, J. Meng, Y. Wang, and C. Li, "Multi-source coordinated control strategy considering battery's SOC for islanded DC microgrid," in High Voltage Engineering, vol. 44, no. 1, pp. 160-168, Jan. 2018.

[12] M. Mao, Q. Cheng, and Y. Ding, "Decentralized coordination power control for islanding microgrid based on PV/BES-VSG," in CPSS Transactions on Power Electronics and Applications, vol. 3, no. 1, pp.14 24, Mar. 2018.

[13] J. Meng, P. Zou, Y. Wang, and C. Wang, "Small-signal modeling and parameter analysis of the DC microgrid based on flexible virtual inertia control," in Transactions of China Electrotechnical Society, vol. 34, no. 12, pp. 2615-2626, Jun. 2019.

[14] J. Meng, M. Song, Y. Wang, and J. Peng, "Multi-constraint stable operation boundary of grid-connected voltage source converter of DC microgrid with virtual capacitance control," in Automation of Electric Power Systems, vol. 43, no. 15, pp. 172-179, 2019.

[15] P. Li, C. Zhang, Z. Kan, and B. Ben, "An integrated Buck-Boost CLLC bidirectional DC converter with high gain and soft switching," in Proceedings of the CSEE, vol. 38, no. 11, pp. 3295-3305, Jun. 2018.

[16] W. Lin, X. Guo, and C. Huang, "Bi-directional DC-DC converters with large conversion ratio based on improved one-cycle control," in Proceedings of the CSEE, vol. 32, no. 21, pp. 31-37, 2012.

[17] H. Tarzamni, P. Kolahian, A. Nikafrooz, and M. Hamzeh, "A multi-port DC-DC Converter for Bipolar MVDC micro-grid applications," in IET Power Electronics, vol. 12, no. 7, pp.1841-1849, Mar. 2019.

[18] Y. K. Tran, F. D. Freijedo, and D. Dujic, "Open-loop power sharing characteristic of a three-port resonant LLC converter," in CPSS Transactions on Power Electronics and Applications, vol. 4, no. 2, pp. 171-179, Jun. 2019.

[19] G. Cao, K. Sun, S. Jiang, S. Lu, and Y. Wang, "A modular DC/DC photovoltic generation system for HVDC grid connection," in Chinese Journal of Electrical Engineering, vol. 4, no. 2, pp. 56-64, Jun. 2018.

[20] A. Sangwongwanich, G. Angenendt, S. Zurmuhlen, Y. Yang, D. Sera, D. U. Sauer, and F. Blaabjerg, "Enhancing PV inverter reliability with battery system control strategy," in CPSS Transactions on Power Electronics and Applications, vol. 3, no. 2, pp. 93-101, Jun. 2018. 


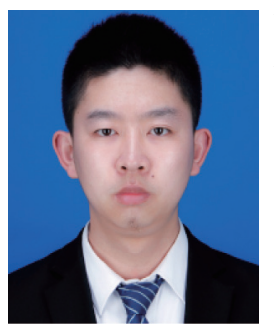

Yuxin Liang received the Master's Degree from Xi'an University of Technology, Xi' an, China, in 2020. The main research direction is virtual inertia control technology of Multi-port CLLC resonant converter for DC micro-grid.

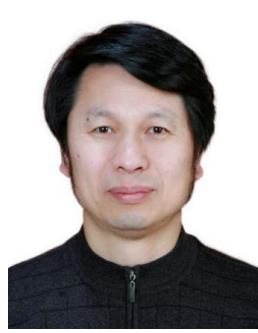

Hui Zhang received the Ph.D. degree in power electronics from the Huazhong University of Science and Technology, Wuhan, China, in 2001. $\mathrm{He}$ is currently a Professor with the Department of Electrical Engineering, Xi'an University of Technology, Xi'an. His research interests include transportation electrification, microgrids, and energy storage.

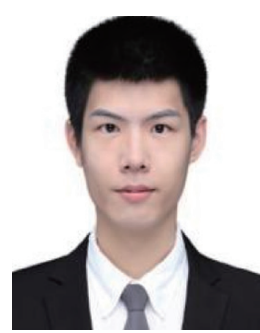

Mingqiao Du received the B.S. degree from Xi'an Jiaotong University City College, Xi' an, China, in 2018. He is currently working toward the Graduate degree in the School of Electrical Engineering, Xi'an University of Technology and receiving joint training from the Department of electrical engineering, Tsinghua University. His research interests include power electronic system stability analysis and coordination control of AC/DC micro-grids.

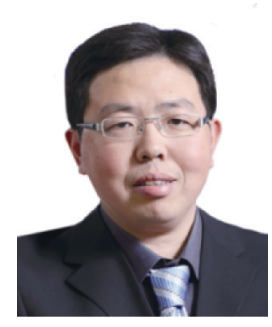

Kai Sun received the B.E., M.E., and Ph.D. degrees in electrical engineering from Tsinghua University, in 2000, 2002, and 2006, respectively. He joined the faculty of Electrical Engineering, Tsinghua University, in 2006, where he is currently an Associate Professor. From Sep. 2009 to Aug. 2010, he was a Visiting Scholar at Department of Energy Technology, Aalborg University, Aalborg, Denmark. From Jan. to Aug. 2017, he was a Visiting Professor at Department of Electrical and Computer Engineering, University of Alberta, Edmonton, Canada. His current research interests include power electronics for renewable generation systems, microgrids, and energy internet.

Dr. Sun serves as an Associate Editor for IEEE Transactions on Power Electronics, IEEE Journal of Emerging and Selected Topics in Power Electronics, and Journal of Power Electronics. Dr. Sun served as the TPC Vice Chair of IEEE ECCE2017 and IEEE ECCE-Asia2017, the Organization Committee Chair of IEEE eGrid2019, and the Publicity Chair of IEEE ECCE2020. He also served as the General Co-Chair of 2018 International Future Energy Challenge (IFEC2018). He was a recipient of Delta Young Scholar Award in 2013, and Youth Award of China Power Supply Society (CPSS) in 2017. 